
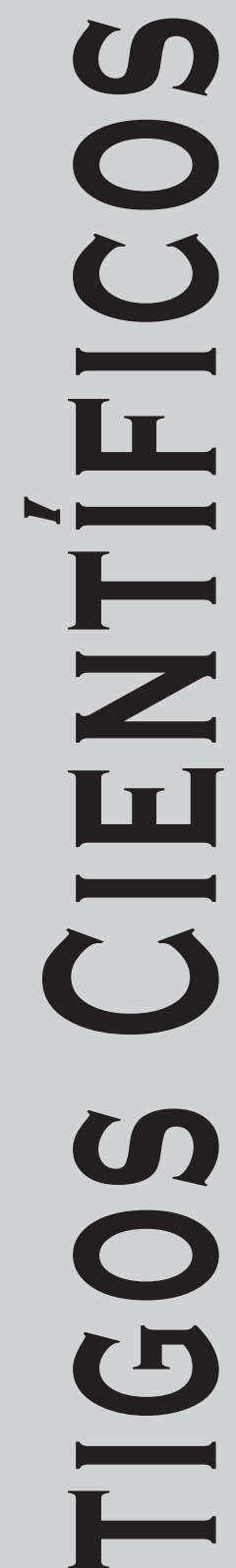
ac

Revista Música Hodie, Goiânia - V.14, 238p., n.1, 2014 


\title{
Um Tipo de Contraponto Existente no Espaço-tempo Intervalar
}

\author{
Aluizio Arcela (Universidade de Brasília, Brasília, DF)
} arcela@cic.unb.br

\begin{abstract}
Resumo: Com base no modelo das árvores de tempos, discute-se a decifração do contraponto a duas vozes que se cria quando o intervalo musical está em equilíbrio. Neste sentido, parte-se da propriedade segundo a qual o intervalo pode assumir dois estados acústicos, quais sejam, o estado alto e o estado baixo, havendo em cada um deles uma coleção decifrável de padrões rítmicos e melódicos. No caso específico do equilíbrio, quando o intervalo está na fronteira entre os estados alto e baixo, surgirão de forma espontânea duas melodias concorrentes, as quais estabelecerão um contraponto supostamente bem formado e com grau de coesão relevante. O cálculo e a escrita de tal estrutura contrapontística são o tema central deste artigo.

Palavras-chave: Contraponto intervalar; Composição formal; Modelo para o intervalo musical; Árvores de tempos.
\end{abstract}

A Type of Counterpoint Which Exists in the Space-time of Intervals

Abstract: From the model of time trees, it is discussed in this paper the deciphering of the two-voice counterpoint that arises when the musical interval is in equilibrium. The starting point is the assumption that any just interval has two acoustic states, namely, the high state and low state, so that there exists in each of them a certain collection of characteristic rhythmic and melodic patterns, ready to be deciphered. in the specific case of the equilibrium, when the interval is at the boundary between the high and low states, two concurrent melodies arise spontaneously, which provide a counterpoint supposedly well formed and having a relevant degree of cohesion. The calculation and the writing of such a contrapuntal structure are the main focus of this article.

Keywords: Intervallic counterpoint; Formal composition; Model for the musical interval; Time trees.

\section{Introdução}

A extração de melodias elementares bem formadas do interior de intervalos musicais $^{1}$ é um assunto abordado em ARCELA, 2012, onde se propõe a análise da épura de árvores de tempos ${ }^{2}$ como critério norteador para se obter um posicionamento significativo do objeto intervalar ${ }^{3}$ no espaço euclidiano. Posicionamento significativo é aquele em que se produz uma melodia que poderá ser considerada como um fragmento autêntico de música, quando avaliada por um número razoável de ouvintes, sobretudo músicos e apreciadores da música em geral. O conceito de espaço-tempo intervalar ${ }^{4}$ aqui introduzido se sustenta na combinação do espaço euclidiano relativo aos intervalos musicais com o tempo estruturado por meio das árvores de tempos.

Para a criação de vozes completas com esta técnica, é necessário proceder-se com o cálculo de uma sucessão de frases - isto é, melodias elementares - que se decifram por meio das mencionadas épuras. Neste sentido, embora haja diferentes maneiras de se fazer o cálculo e a emenda das frases melódicas, uma delas parece ser mais forte. Trata-se da técnica de se dispor em contiguidade uma sequência de melodias geradas por objetos intervalares de segunda ordem, isto é, objetos representantes de intervalos musicais secundários, que se criam nas próprias árvores de tempos pertencentes a um objeto intervalar primal 5 . Desta forma, produzem-se sucessivas transformações algébrico melódicas, as quais propiciarão um crescimento espontâneo na dimensão melódica, isto por meio de frases que têm entre si um certo grau de parentesco estrutural. Portanto, é este procedimento que poderá levar uma voz construída a ter o predicado de ser bem formada.

No caso do presente artigo, a abordagem limita-se às manifestações polifônicas mais primitivas no interior do mencionado espaço-tempo intervalar. Especificamente, o que se discute são as bases polifônicas de um sistema composicional que faz uso do conteúdo e 
da topologia ${ }^{6}$ de árvores de tempos combinadas com a cinemática de objetos intervalares ${ }^{7}$. O primeiro e mais importante comportamento contrapontístico espontâneo que aí se observa ocorre quando o intervalo está em equilíbrio (v. ARCELA, 2008).

De acordo com o modelo denominado objeto intervalar, todo intervalo pode assumir dois estados acústicos, quais sejam, o estado alto e o estado baixo, havendo em cada um deles uma determinada coleção de padrões rítmicos característicos. O posicionamento sistemático e apurado do intervalo no espaço euclidiano tridimensional conferirá melodias a esses padrões, que são estruturas de tempos, de alturas (pitch) e de níveis de intensidade acústica, de tal maneira que se podem calcular melodias distintas em cada um dos estados.

No caso específico do equilíbrio intervalar ${ }^{8}$ - que é uma situação atingida por uma parametrização que coloca o intervalo bem no limite entre os estados alto e baixo -, haverá espontaneamente uma ação recíproca de duas melodias concorrentes, as quais estabelecerão um contraponto bem formado e com grau de coesão relevante ${ }^{9}$, a depender, entretanto, de se determinar um posicionamento significativo para o objeto intervalar.

Evidentemente que há neste processo de construção contrapontística diferenças básicas com relação às técnicas de contraponto que se conhecem historicamente, isto desde o tratado de Gioseffo Zarlino escrito no século XVI (v. ZARLINO, 1968), até os textos do século XX (por exemplo, KRONEK, 1940; SCHOENBERG, 1963; OWEN, 1992). No caso do contraponto com as árvores de tempos, as duas vozes (cada qual contendo uma única frase melódica, que é proveniente do respectivo objeto intervalar - em um dos estados alto ou baixo) serão superpostas por inteiro no espaço-tempo intervalar, e não nota a nota. $\mathrm{O}$ fato de elas se associarem naturalmente advém da relação de parentesco estrutural que há entre as duas, a qual se deve à condição de representarem em conjunto as duas faces (acústico musicais) de um mesmo intervalo.

\section{Ritmos decifrados e melodias viáveis}

Os ritmos que se podem extrair das florestas de tempos resultam da circunstância temporal, isto é, eles dependem tanto da ordem cronológica dos nodos das árvores - nodos estes que se constituem nos chamados eventos intervalares - quanto das durações desses nodos. Os eventos intervalares traduzem-se em notas musicais que surgem ao longo de um período do intervalo, denominado -, cuja extensão mede 2mn passos (ARCELA, 2013, Chapter 2). Ao longo de um período $\tau$, coleta-se uma sequência de durações da floresta por meio de um tipo especial de percurso em árvores ${ }^{10}$ que se denomina "primeiro em largura", o qual se resume em caminhar-se nível a nível nas árvores, visitando-se sequencialmente os nodos contíguos de um mesmo nível, sempre da esquerda para a direita, e com início no nodo raiz da primeira árvore de tempos (ARCELA, 2014).

Evidentemente que, neste sistema musical, haverá infinitas melodias possíveis para um número finito de ritmos decifráveis (ver LAMUS, 2013b), as quais se calculam quando os eventos intervalares ${ }^{11}$ acima mencionados são considerados não só na circunstância temporal, mas também na sua realidade geométrica, isto é, como pontos do espaço euclidiano. Mais especificamente, cada um desses pontos poderá ser convertido em nota musical, já que todos eles possuem posição e velocidade próprias, sendo ambas calculáveis por meio da cinemática do movimento intervalar, movimento este que resulta da combinação de dois movimentos periódicos ${ }^{12}$, sendo, um deles, um movimento harmônico simples - justamente aquele com maior força da altura ${ }^{13}$ e que, por esta razão, define o estado do intervalo - e, o outro, um movimento circular e uniforme. 
Uma propriedade do espaço-tempo intervalar de grande impacto para os sistemas de composição é que apenas algumas melodias obtidas com esses sistemas apresentam conteúdo musical suficiente para serem consideradas verdadeiras ou, mais precisamente, viáveis. Isto ocorre porque as melodias viáveis são singularidades do espaço-tempo intervalar, isto é, são raridades em meio a uma infinidade de melodias falsas. E é neste contexto que a busca por melodias viáveis torna-se uma das etapas principais, e talvez a mais complexa, do método de composição que se baseia nas árvores de tempos ${ }^{14}$.

A melodia estará pronta para ser calculada depois que o objeto intervalar estiver posicionado e orientado no espaço euclidiano tridimensional, lugar em que as grandezas cinemáticas do movimento combinado devem ser computadas a cada nodo das árvores (do particular intervalo), de modo a fornecer os dados restantes, isto é, altura e intensidade. Conhece-se antecipadamente a duração de cada nota, porque ela sempre será dada pelo próprio conteúdo numérico do nodo (v. ARCELA, 2013, Chapter 6), que representa o seu tempo de existência, isto é, a sua vigência na melodia. Deste modo, a extinção de um nodo coincidirá com o surgimento do nodo subsequente.

De acordo com o exposto acima, para se dar início ao cômputo de uma melodia, os parâmetros principais do objeto intervalar - juntamente com as três transformações básicas, quais sejam, posição, orientação e fatores melódicos - já devem estar valorados. A posição do objeto intervalar é definida pelas coordenadas cartesianas de seu centro [ $\left.p_{\mathrm{x}} p_{\mathrm{y}} p_{\mathrm{z}}\right]$, enquanto que a orientação é definida por meio dos chamados ângulos de rotação de Euler $\left[\rho_{\mathrm{x}} \rho_{\mathrm{y}} \rho_{\mathrm{z}}\right.$ ] em torno dos eixos $x, y$ e $z$, respectivamente. Os fatores melódicos, isto é, fator de andamento, fator de transposição e fator de dinâmica, constituem a terceira e última transformação básica (ver ARCELA, 2014).

\section{Contraponto intervalar}

Do ponto de vista do modelo das árvores de tempos (ARCELA, 2013), que é o segundo estágio do modelo para o intervalo, o que se denomina contraponto intervalar é a ação recíproca de duas melodias concorrentes que se estabelecem quando o intervalo musical encontra-se em equilíbrio (ver ARCELA, 2008, Section 2.2). A decifração contrapontística é, pois, algo pertencente ao domínio da composição formal ${ }^{15}$, tanto quanto o são os métodos descritos por alguns autores, como XENAKIS, 1957; HILLER, 1964; LINDBLOM e SUNDBERG, 1969; LERDHAL e JAKENDOFF, $1983 .^{16}$

De acordo com o modelo das árvores de tempos, em um intervalo musical justo, cuja razão de frequências é [m: $n$ - sendo $m$ e $n$ números inteiros primos entre si - há $n$ ritmos passíveis de decifração no estado baixo, enquanto que no estado alto há $m$ ritmos. E se há infinitas melodias que podem ser atribuídas a cada um desses ritmos que se definem nos estados intervalares, conforme mencionado acima na Seção 2, será porque há infinitas maneiras de se posicionar e orientar o objeto intervalar no espaço euclidiano. Quando o intervalo se encontra no estado baixo e, além disto, está devidamente, ou de alguma maneira, posicionado e orientado no espaço, define-se aí uma única melodia. Da mesma forma, estando o intervalo no estado alto, criar-se-á uma outra melodia, também única.

Já no equilíbrio - que é uma condição singular e própria de cada intervalo - surgem duas melodias concorrentes, supostamente como se fossem nascidas uma para a outra. A despeito da importância deste fato para a construção formal da música, especialmente da música polifônica, não se pode dizer que se trata de um resultado de todo surpreendente. Em última análise, a existência dessas duas melodias simultâneas é a condição mais pro- 
funda para que o intervalo esteja verdadeiramente em equilíbrio. Portanto, é na condição de equilíbrio que se estabelece o assim chamado contraponto intervalar.

Em suma, o equilíbrio é uma coexistência de dois objetos intervalares superpostos, cujos parâmetros são conjugados. Isto é, os parâmetros do movimento harmônico simples de um objeto correspondem aos parâmetros do movimento circular uniforme do outro objeto, e vice-versa. Por definição, os dois objetos coexistentes no equilíbrio intervalar são tais que um deles pertence ao estado baixo, enquanto o outro pertence ao alto (ver Seção 4 sobre o ajuste infinitesimal na proporção de amplitudes). Estes dois objetos que modelam e dão vida ao equilíbrio são aqui denominados objetos intervalares conjugados.

Uma vez que os movimentos circulares podem girar em sentido horário ou em sentido anti-horário, a ordenação cronológica das notas de cada uma das duas melodias poderá ser direta ou retrógrada, considerando-se que há quatro possíveis conjugações para cada par de melodias intervalares (alto e baixo) encontradas. Isto é, haverá as conjugações $D D$ (ordenação direta $\times$ ordenação direta), $D R$ (ordenação direta $\times$ ordenação retrógrada), $R D$ (ordenação retrógrada $\times$ ordenação direta), e a $R R$ (ordenação retrógrada $\times$ ordenação retrógrada). Assume-se que uma dada melodia será de ordenação retrógrada se o movimento circular uniforme do respectivo objeto intervalar tiver o sentido horário. E, portanto, se o movimento circular tiver o sentido anti-horário, a melodia será de ordenação direta.

Uma última propriedade do contraponto intervalar a ser observada consiste no fato de que as duas melodias se iniciam em momentos distintos, uma vez que haverá sempre uma diferença de tempo entre o surgimento da primeira nota do objeto conjugado baixo e o surgimento da primeira nota do objeto conjugado alto. E como ambas as melodias têm a mesma duração - correspondendo justamente a um período do objeto intervalar - a melodia tardia continuará por mais um pouco após o término da melodia pontual. Isto é, ela prosseguirá soando sozinha pelo mesmo tempo que esperou para entrar. A este respeito, conforme ilustram os exemplos abaixo, as tais melodias concorrentes se iniciam naturalmente em momentos distintos, às vezes próximos, às vezes distantes, a depender dos valores das ordens de frequência m e n, e dos ângulos de fase inicial dos movimentos harmônicos simples dos dois objetos intervalares conjugados que constituem o intervalo em estado de equilíbrio.

Com o fim de ilustrar a existência de estruturas musicais no espaço-tempo dos intervalos, descrevem-se a seguir três exemplos contrapontísticos $C_{\underline{1}}, C_{\underline{2}}$ e $C_{\underline{3}}$, sendo a descrição do contraponto $C_{1}$ um pouco mais detalhada do que a dos demais, especialmente na ilustração da decifração dos ritmos, assim como na determinação de uma melodia viável para um dado ritmo decifrado. Nos dois exemplos subsequentes, essas duas etapas iniciais são análogas às do primeiro exemplo e, portanto, são omitidas.

\section{Contraponto $C_{1}$ no interior de uma terça menor [5:6]}

Neste primeiro exemplo, estuda-se o intervalo de uma terça menor [5:6] cujo primeiro objeto intervalar conjugado - aquele que se encontra ligeiramente no estado baixo - é tal que os seus parâmetros, quais sejam, posição do centro [ $\left.p_{\mathrm{x}} p_{\mathrm{y}} p_{z}\right]$, orientação segundo ângulos de Euler $\left[\rho_{\mathrm{x}} \rho_{\mathrm{y}} \rho_{\mathrm{z}}\right.$ ], assim como as ordens de frequência $m$ e $n$ da razão intervalar [m: $\left.n\right]$, como também a amplitude (a) do movimento harmônico simples (MHS), a sua fase inicial $(\varphi)$, juntamente com o raio (b) do movimento circular uniforme (MCU), o seu giro inicial $(\theta)$, e ainda os fatores melódicos $k_{\mathrm{A}}$ para o andamento, $k_{\mathrm{T}}$ para transposição e $k_{\mathrm{D}}$ para a dinâmica, estão mostrados na Tabela 1. Este primeiro objeto intervalar contém a melodia $M_{1 \mathrm{~B}}$ 
do contraponto $C_{1}$. Sendo a relação de equilíbrio dada por (ver ARCELA, 2008, Section 2.2), o valor do raio (b) do MCU será um pouco reduzido (teoricamente por um infinitésimo), de tal maneira que o objeto pertencerá ligeiramente ao estado baixo.

Tabela 1: Primeiro objeto intervalar conjugado de uma terça menor [5:6] ligeiramente no estado baixo.

\begin{tabular}{|c|c|c|c|c|c|c|c|c|c|c|c|c|c|c|c|c|}
\hline & $a$ & $m$ & $\varphi$ & $b$ & $n$ & $\theta$ & $p_{x}$ & $p_{y}$ & $p_{z}$ & $\rho_{x}$ & $\rho_{y}$ & $\rho_{z}$ & $k_{A}$ & $k_{T}$ & $k_{D}$ & sentido \\
\hline MHS & 24 & 5 & 46 & & & & & & & & & & & & & \\
\hline MCU & & & & 16,665 & 6 & 244 & & & & & & & & & & Anti-horário \\
\hline Posição & & & & & & & -12 & -40 & -18 & & & & & & & \\
\hline Orientação & & & & & & & & & & 174 & 209 & 244 & & & & \\
\hline Fatores & & & & & & & & & & & & & 7 & 7 & 2 & \\
\hline
\end{tabular}

Para se obter o segundo objeto intervalar conjugado desta terça menor [5:6], considera-se mais uma vez a relação de equilíbrio $a m^{2}=b n^{2}$ como ponto de partida, e aumenta-se um pouco (teoricamente um infinitésimo) o valor do parâmetro $b$ - correspondente ao raio do MCU do primeiro objeto - de modo a tornar-se agora a amplitude do novo MHS. Assim, o segundo objeto conjugado pertencerá ligeiramente ao estado alto. Em seguida, o valor do parâmetro $a$, correspondente à amplitude do MHS do primeiro objeto conjugado, deverá torna-se o raio do novo MCU, cujo sentido de rotação é horário, de modo que a ordenação melódica correspondente será retrógrada. Os parâmetros deste segundo objeto intervalar conjugado da terça menor [5:6] encontram-se na Tabela 2. A melodia $M_{1 \mathrm{~A}}$ do contraponto $C_{1}$ está contida neste objeto.

Tabela 2: Segundo objeto intervalar conjugado de uma terça menor [5:6] ligeiramente no estado alto.

\begin{tabular}{|c|c|c|c|c|c|c|c|c|c|c|c|c|c|c|c|c|}
\hline & $a$ & $m$ & $\varphi$ & $b$ & $n$ & $\theta$ & $p_{x}$ & $p_{y}$ & $p_{z}$ & $\rho_{x}$ & $\rho_{y}$ & $\rho_{z}$ & $k_{A}$ & $k_{T}$ & $k_{D}$ & sentido \\
\hline MCU & 24 & 5 & 46 & & & & & & & & & & & & & Horário \\
\hline MHS & & & & 16,667 & 6 & 244 & & & & & & & & & & \\
\hline Posição & & & & & & & -12 & -40 & -18 & & & & & & & \\
\hline Orientação & & & & & & & & & & 174 & 209 & 244 & & & & \\
\hline Fatores & & & & & & & & & & & & & 7 & 7 & 2 & \\
\hline
\end{tabular}

Para se compor um contraponto intervalar, a primeira consideração consiste em se identificar o conjunto de árvores em cada um dos estados alto e baixo, uma vez que o estado de equilíbrio - conforme mencionado na Seção 3 e ilustrado nas Tabelas 1 e 2 - consolida-se na convivência espaço temporal de dois objetos quase iguais do ponto de vista de seus parâmetros, mas que são na realidade objetos intervalares em estados diferentes. Isto causará árvores de tempos diferentes em cada um dos dois objetos, assim como as geometrias serão distintas e, portanto, os ritmos e as melodias serão distintos e contrapontísticos.

Desta maneira, neste primeiro exemplo, verifica-se que há três árvores de tempos na floresta $A_{1}$ de uma terça menor justa [5:6] no estado baixo, na sua terceira mutação (v. ARCELA, 2013, Chapter 5), conforme ilustra a Figura 1. Tal floresta $A_{1}$ é uma das seis hierarquias temporais que se podem criar no interior de uma terça menor-5:6 no estado baixo.

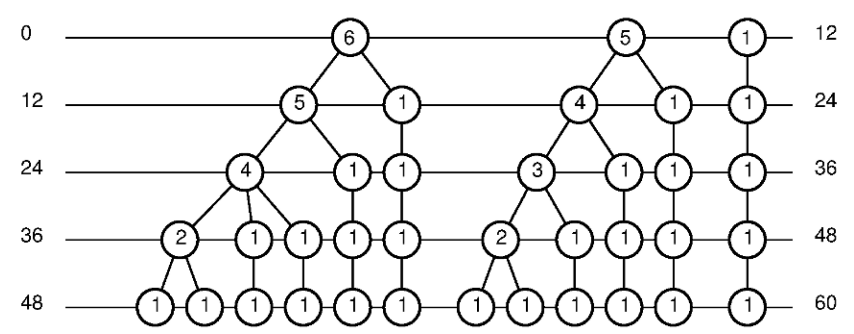

Figura 1: Floresta $A_{1}$ de árvores de tempos do intervalo 5:6-terça maior no estado baixo, $3^{a}$ mutação, do $=12$. 
A coleta de notas na floresta $\mathrm{A}_{1}$ se inicia no nodo raiz da árvore mais à esquerda, isto é, a duração $\{6\}$, que é seguida pela raiz da segunda árvore $\{5\}$ e, então, como último elemento do primeiro nível (ou geração) da floresta, o nodo raiz da terceira árvore \{1\} é coletado. Em seguida, considera-se a segunda geração de durações, de modo que os dois nodos descendentes $\left\{\begin{array}{ll}5 & 1\end{array}\right\}$ da primeira raiz são coletados, aí então tomam-se os descendentes $\left\{\begin{array}{l}4 \\ 1\end{array}\right\}$ da raiz da segunda árvore e, finalmente neste segundo nível, toma-se o descendente $\{1\}$ da terceira árvore. Em seguida, a terceira geração produz $\left\{\begin{array}{lll}4 & 1 & 1\end{array}\right\},\left\{\begin{array}{llll}3 & 1 & 1\end{array}\right\}$ e $\left\{\begin{array}{ll}1\end{array}\right\}$. A quarta geração por sua vez produz \{2 1111 1\}, \{2 111 1\} e \{1\}. Finalmente, a quinta geração produz $\left\{\begin{array}{lllllll}1 & 1 & 1 & 1 & 1\end{array}\right\},\left\{\begin{array}{llllll}1 & 1 & 1 & 1 & 1\end{array}\right\}$ e $\{1\}$.

Uma vez que o contraponto $C_{1}$ é uma conjugação contrapontística do tipo $R D$, a voz baixo estará sob ordenação retrógrada. Desta maneira, quando se unem todas as gerações enumeradas acima, e inverte-se a ordem dos termos, obtém-se a sequência de durações $D_{1 \mathrm{~B}}$ $=\{1111111111111111211112111311411415156\}$ para as notas da voz baixo do contraponto $C_{1}$.

Assumindo-se que a menor duração na sequência $D_{1 \mathrm{~B}}$ - isto é, a unidade $\{1\}$ corresponde a uma semicolcheia, produz-se então a estrutura rítmica $R_{1 \mathrm{~B}}$ que se exibe na Figura 2 para a voz baixo do contraponto.

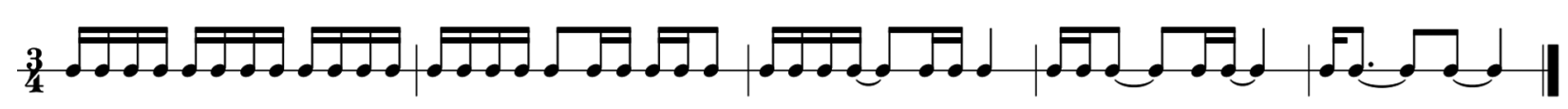

Figura 2: Ritmo $R_{1 \mathrm{~B}}$ definido pela sequência de durações $D_{1 \mathrm{~B}}$.

Levando-se em conta que as notas de $R_{1 \mathrm{~B}}$ correspondem a pontos do objeto intervalar cujas posições e velocidades são conhecidas, podem-se calcular para cada uma delas as grandezas acústicas correspondentes (v. ARCELA, 2013, Chapter 6, Calculating Notes), de maneira que se podem agregar a cada elemento da sequência de durações os devidos valores de altura e intensidade, a fim de se completar o cômputo de cada nota. Graças a esses cálculos, a estrutura rítmica $R_{1 \mathrm{~B}}$ poderá ser mapeada para a melodia $M_{1 \mathrm{~B}}$, conforme se exibe na Figura 3.

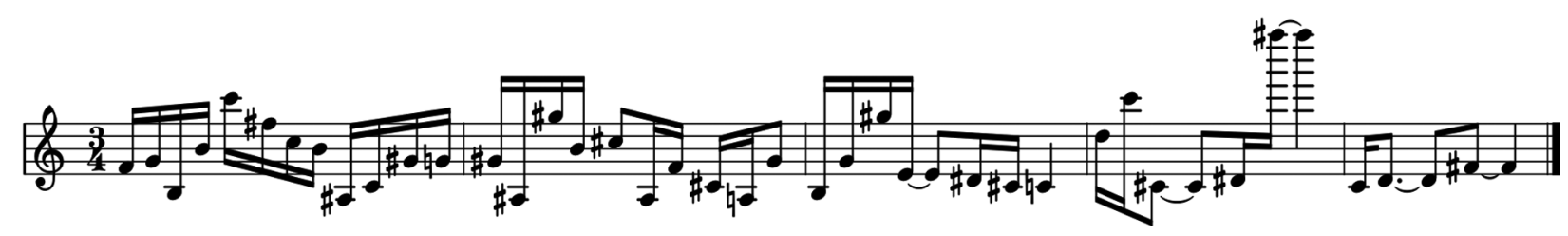

Figura 3: Melodia $M_{1 \mathrm{~B}}$ para o ritmo $R_{1 \mathrm{~B}}$.

Para o segundo objeto - que é do estado alto, e é conjugado ao objeto do estado baixo - há duas árvores de tempos na floresta $\Omega_{1}$, neste caso de uma terça menor justa [5:6] na sua terceira mutação, conforme ilustra a Figura 4. Tal floresta $\Omega_{1}$ é uma das cinco hierarquias temporais que se podem criar no interior de uma terça menor-5:6 no estado alto.

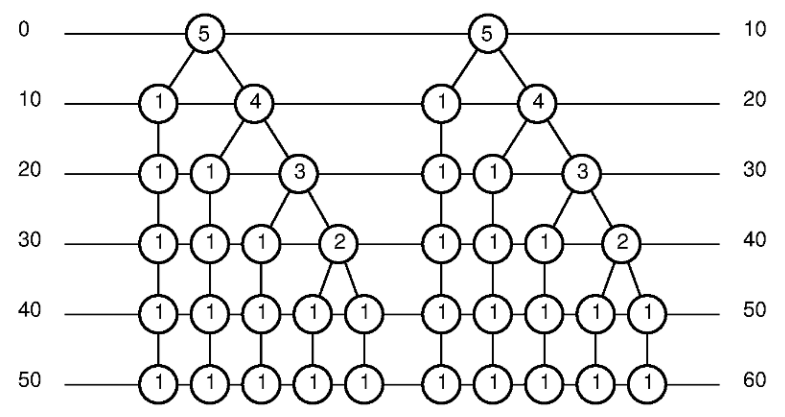

Figura 4: Floresta $\Omega_{1}$ de árvores de tempos do intervalo 5:6-terça maior no estado alto, $5^{\text {a }}$ mutação, do $=16$. 
A coleta de notas na floresta $\Omega_{1}$ se inicia no nodo raiz da árvore mais à esquerda, isto é, a duração $\{5\}$, que é sucedida pela raiz da segunda árvore $\{5\}$. Em seguida, conside-

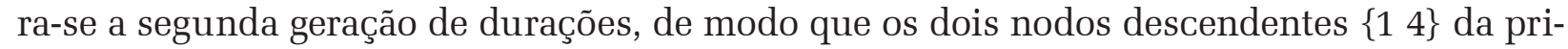
meira raiz são coletados, quando então se tomam os descendentes $\{14\}$ da raiz da segunda árvore. A terceira geração produz $\left\{\begin{array}{lll}1 & 1 & 3\end{array}\right\}$ e $\left.\begin{array}{lllll}1 & 1 & 3\end{array}\right\}$. A quarta geração, por sua vez, produz $\{1$ $\left.\begin{array}{lll}1 & 1 & 2\end{array}\right\}$ e $\left\{\begin{array}{llll}1 & 1 & 1 & 2\end{array}\right\}$. A quinta geração produz $\left\{\begin{array}{lllll}1 & 1 & 1 & 1 & 1\end{array}\right\}$ e $\left\{\begin{array}{llllll}1 & 1 & 1 & 1 & 1\end{array}\right\}$. E, finalmente, a sexta geração produz $\left\{\begin{array}{lllllll}1 & 1 & 1 & 1 & 1\end{array}\right\}$ e $\left\{\begin{array}{llllll}1 & 1 & 1 & 1 & 1\end{array}\right\}$.

Outra vez, considerando-se que, por construção, $C_{1}$ é uma construção contrapontística do tipo $R D$, a voz alto, diferentemente da voz baixo descrita acima, estará sob ordenação direta. Desta maneira, quando se unem as gerações de durações extraídas da floresta $\Omega_{1}$, obtém-se a sequência de durações $D_{1 \mathrm{~A}}=\{\{4\} 55141411311311211112111$ 2111111111111111 \} para as notas da voz alto do contraponto.

Assumindo-se que a menor duração na sequência $D_{1 \mathrm{~A}}$ - isto é, a unidade $\{1\}$ corresponde a uma semicolcheia, produz-se então a estrutura rítmica $R_{1 \mathrm{~A}}$ que se exibe na Figura 5 para a voz alto do contraponto.

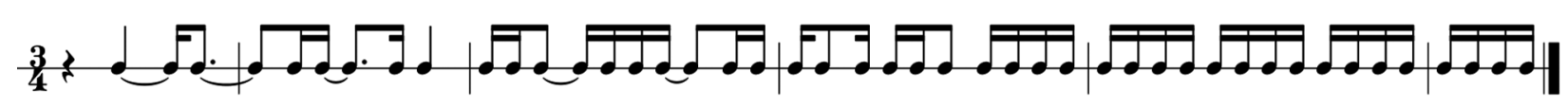

Figura 5: Ritmo $R_{1 A}$ definido pela sequência de durações $D_{1 A}$.

De modo semelhante ao empregado na voz baixo, uma melodia $M_{1 \mathrm{~A}}$ que seja viável para este ritmo $R_{1 \mathrm{~A}}$ deverá ser calculada. A primeira duração $D_{1 \mathrm{~A}}$, que se representa por $\{\{4\} \ldots\}$, indica que $M_{1 \mathrm{~A}}$ é a melodia tardia, uma vez que a primeira nota da melodia alto se inicia com um retardo de $\{4\}$ unidades de tempo (passos) relativamente ao início da primeira nota da melodia baixo $M_{1 \mathrm{~B}}$. Esta é a razão da pausa de semínima ao início do ritmo $R_{1 \mathrm{~A}}$. A Figura 6 mostra a melodia $M_{1 \mathrm{~A}}$ da voz alto, melodia esta que é indissociável de $M_{1 \mathrm{~B}}$ da voz baixo, considerando-se que se trata de sua contrapartida intervalar.

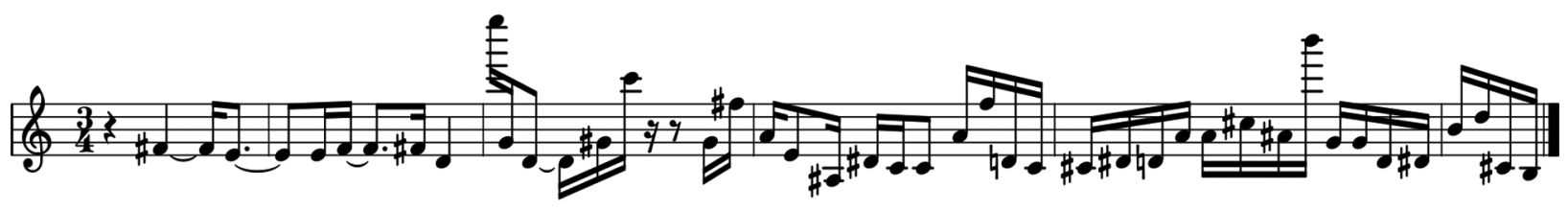

Figura 6: Melodia $\mathrm{M}_{1 \mathrm{~A}}$ para o ritmo $\mathrm{R}_{1 \mathrm{~A}}$.

Em síntese, a partir das sequências de durações produzidas pelas florestas $A_{1}$ e $\Omega_{1}$, e do emprego devido da cinemática intervalar, duas melodias são construídas, isto é, $M_{1 \mathrm{~B}} \mathrm{e}$ $M_{1 \mathrm{~A}}$. A Figura 7 mostra a disposição em contraponto destas melodias calculadas para cada um dos estados alto e baixo do intervalo, depois que o objeto intervalar é posicionado no espaço. A escrita se faz em cinco compassos em uma fórmula de compasso de $3 / 4$, uma vez que a duração total da sequência é de 60 passos de tempo $(\tau=2 m n=2 \times 5 \times 6)$. Em outras palavras, dispondo-se 12 passos (isto é, três semínimas) em cada compasso, todo o contraponto $C_{1}$ estará acomodado em cinco compassos. 


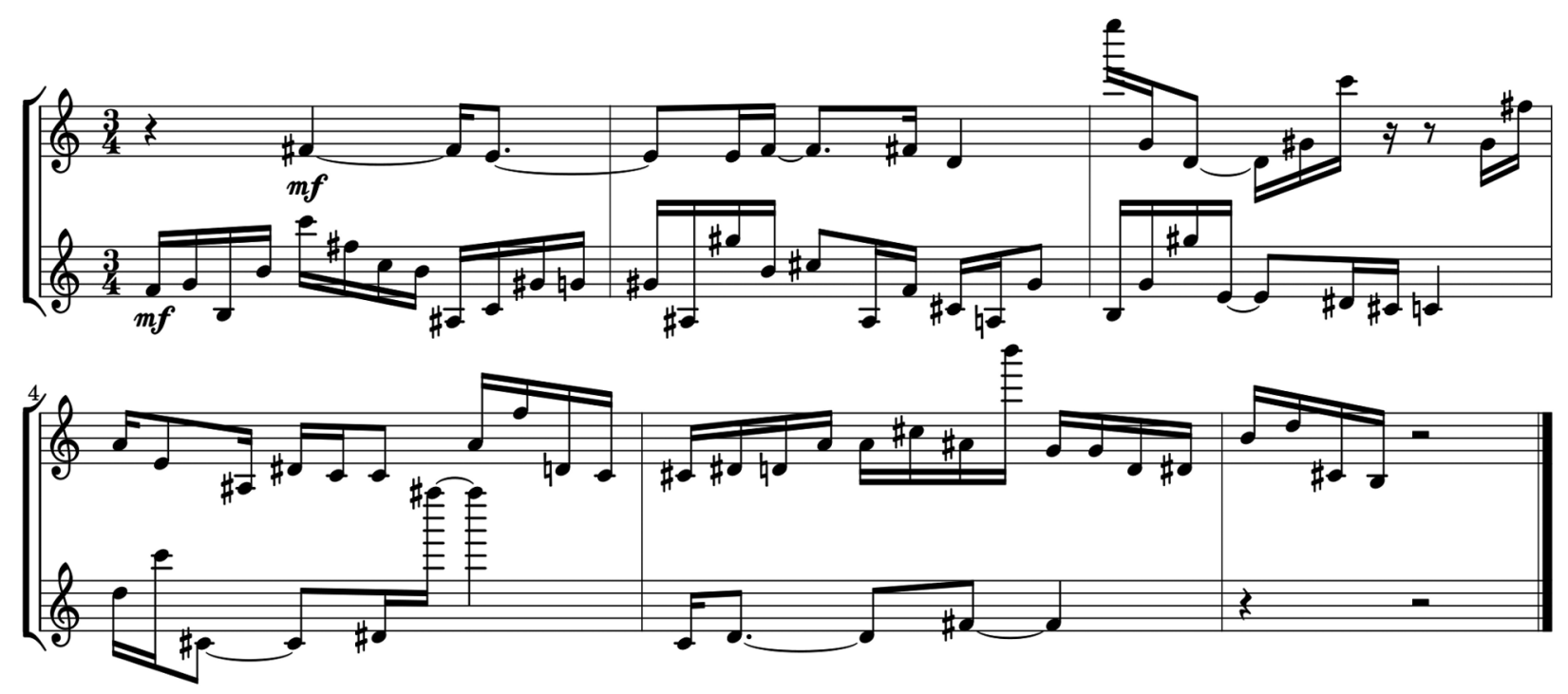

Figura 7: ??????????????????????????????????

\section{Contraponto $C_{2}$ no interior de uma segunda maior [8:9]}

Relativamente ao exemplo anterior, este contraponto $C_{2}$ será descrito de forma mais abreviada, uma vez que os procedimentos iniciais são semelhantes. Fica implícito que os ritmos $R_{2 \mathrm{~B}}$ e $R_{2 \mathrm{~A}}$ serão devidamente decifrados, assim como as melodias $M_{2 \mathrm{~B}}$ e $M_{2 \mathrm{~A}}$ haverão de ser calculadas.

Os parâmetros do primeiro objeto intervalar do equilíbrio primal de uma segunda maior [8:9], quais sejam, posição, orientação, assim como os números ( $m$ e $n$ ) da razão intervalar [m:n], amplitude $(a)$ do MHS, o ângulo de fase inicial $(\varphi)$, juntamente com o raio $(b)$ do MCU, o ângulo de giro inicial $(\theta)$, e os fatores melódicos ( $k_{\mathrm{A}}, k_{\mathrm{T}}$ e $k_{\mathrm{D}}$ ) são mostrados na Tabela 3. A melodia $M_{2 \mathrm{~B}}$ está contida neste objeto intervalar. Sendo a relação de equilíbrio dada por $a m^{2}=b n^{2}$, o raio $b$ do MCU será um pouco reduzido (teoricamente por um infinitésimo), de tal maneira que o objeto pertencerá ligeiramente ao estado baixo.

Tabela 3: Primeiro objeto intervalar conjugado de uma segunda maior [8:9] ligeiramente no estado baixo.

\begin{tabular}{|c|c|c|c|c|c|c|c|c|c|c|c|c|c|c|c|c|}
\hline & $a$ & $m$ & $\varphi$ & $b$ & $n$ & $\theta$ & $p_{x}$ & $p_{y}$ & $p_{z}$ & $\rho_{x}$ & $\rho_{y}$ & $\rho_{z}$ & $k_{A}$ & $k_{T}$ & $k_{D}$ & sentido \\
\hline MHS & 24 & 8 & -1 & & & & & & & & & & & & & \\
\hline MCU & & & & 18,961 & 9 & 244 & & & & & & & & & & Anti-horário \\
\hline Posição & & & & & & & 24 & -2 & 15 & & & & & & & \\
\hline Orientação & & & & & & & & & & 232 & 197 & 255 & & & & \\
\hline Fatores & & & & & & & & & & & & & 11 & 7 & 1 & \\
\hline
\end{tabular}

Quanto ao segundo objeto intervalar conjugado, considera-se mais uma vez a relação de equilíbrio $a m^{2}=b n^{2}$ como ponto de partida, e aumenta-se um pouco (teoricamente um infinitésimo) o valor do parâmetro b - correspondente ao raio do MCU do primeiro objeto - de modo a tornar-se agora a amplitude do novo MHS, de tal maneira que este segundo objeto pertencerá ligeiramente ao estado alto. O valor do parâmetro $a$, correspondente à amplitude do MHS do primeiro objeto conjugado, tornar-se-á o raio do novo MCU, cujo sentido de rotação é anti-horário, de modo que a ordenação melódica correspondente será direta. Os parâmetros deste segundo objeto intervalar conjugado da segunda maior [8:9] estão na Tabela 4. A melodia $M_{2 \mathrm{~A}}$ do contraponto $C_{2}$ está contida neste objeto intervalar. 
Tabela 4: Segundo objeto intervalar conjugado de uma segunda maior [8:9] ligeiramente no estado alto.

\begin{tabular}{|c|c|c|c|c|c|c|c|c|c|c|c|c|c|c|c|c|}
\hline & $a$ & $m$ & $\varphi$ & $b$ & $n$ & $\theta$ & $p_{x}$ & $p_{y}$ & $p_{z}$ & $\rho_{x}$ & $\rho_{y}$ & $\rho_{z}$ & $k_{A}$ & $k_{T}$ & $k_{D}$ & sentido \\
\hline MCU & 24 & 8 & -1 & & & & & & & & & & & & & Anti-horário \\
\hline MHS & & & & 18,963 & 9 & 244 & & & & & & & & & & \\
\hline Posição & & & & & & & 24 & -2 & 15 & & & & & & & \\
\hline Orientação & & & & & & & & & & 232 & 197 & 255 & & & & \\
\hline Fatores & & & & & & & & & & & & & 11 & 7 & 2 & \\
\hline
\end{tabular}

Neste caso de uma segunda maior justa [8:9] como objeto primal, há três árvores de tempos na floresta $\mathrm{A}_{2}$ no estado baixo natural, na sua segunda mutação, conforme ilustra a Figura 8. Tal floresta $A_{2}$ é uma das nove hierarquias temporais que se podem extrair do interior de uma segunda maior-8:9 no estado baixo.

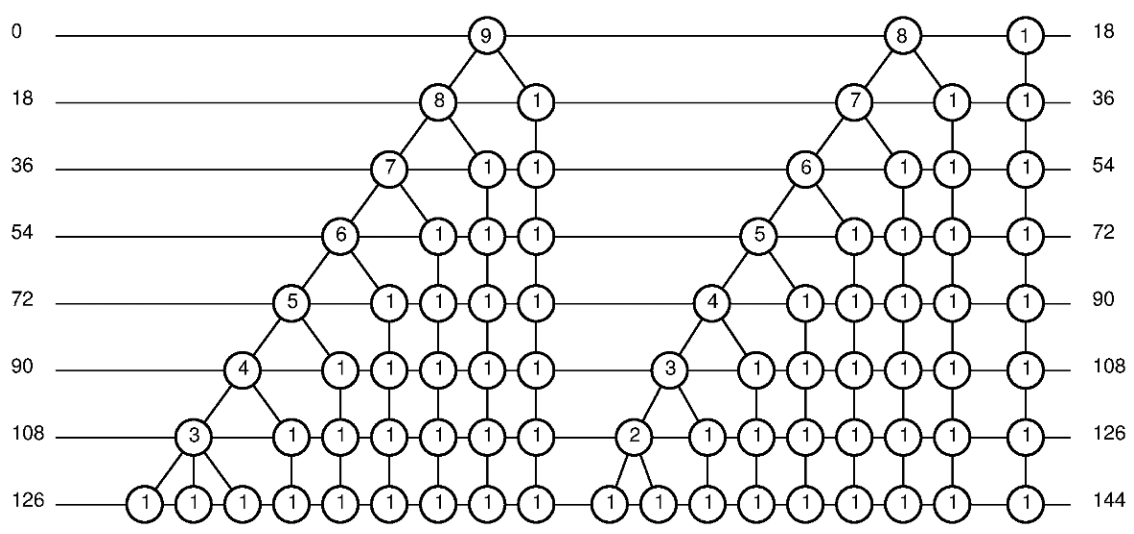

Figura 8: Floresta $A_{2}$ de árvores de tempos do intervalo 8:9-segunda maior no estado baixo, $2^{\mathrm{a}}$ mutação, $\mathrm{d}_{0}=17$.

Assim como se fez na floresta $A_{1}$ acima, a coleta de notas na floresta $A_{2}$ se inicia no nodo raiz da árvore mais à esquerda que, neste caso, é a duração \{9\}, a qual é seguida pela raiz da segunda árvore $\{8\}$ e, então, como último elemento do primeiro nível (ou geração) da floresta, o nodo raiz da terceira árvore $\{1\}$ é coletado. Em seguida, considera-se a segunda geração de durações, de modo que os dois nodos descendentes $\left\{\begin{array}{ll}8 & 1\end{array}\right\}$ da primeira raiz são coletados. Tomam-se então os descendentes $\left\{\begin{array}{ll}7 & 1\end{array}\right\}$ da raiz da segunda árvore e, finalmente neste segundo nível, toma-se o descendente $\{1\}$ da terceira árvore. Em seguida, a terceira geração produz $\left\{\begin{array}{llll}7 & 1 & 1\end{array}\right\},\left\{\begin{array}{lll}6 & 1 & 1\end{array}\right\}$ e $\left\{\begin{array}{l}1\end{array}\right\}$. A quarta geração por sua vez produz $\left\{\begin{array}{llll}6 & 1 & 1 & 1\end{array}\right\}$, $\left\{\begin{array}{llll}5 & 1 & 1 & 1\end{array}\right\}$ e $\{1\}$. A quinta geração produz $\left\{\begin{array}{llllll}5 & 1 & 1 & 1 & 1\end{array}\right\},\left\{\begin{array}{lllll}4 & 1 & 1 & 1 & 1\end{array}\right\}$ e $\{1\}$. A sexta geração produz

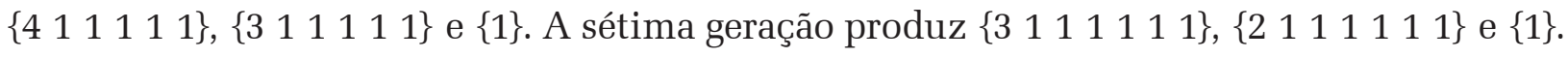
Finalmente, a oitava geração produz $\left\{\begin{array}{lllllllll}1 & 1 & 1 & 1 & 1 & 1 & 1 & 1\end{array}\right\},\left\{\begin{array}{llllllll}1 & 1 & 1 & 1 & 1 & 1 & 1\end{array}\right\}$ e $\{1\}$.

Já no caso do estado alto mostrado na Figura 9, há duas árvores de tempos na floresta $\Omega_{2}$ de uma segunda maior justa [8:9] no estado alto, na sua segunda mutação. Tal floresta $\Omega_{2}$ é uma das oito hierarquias temporais que se podem criar no interior de uma segunda maior justa [8:9] no estado alto. 


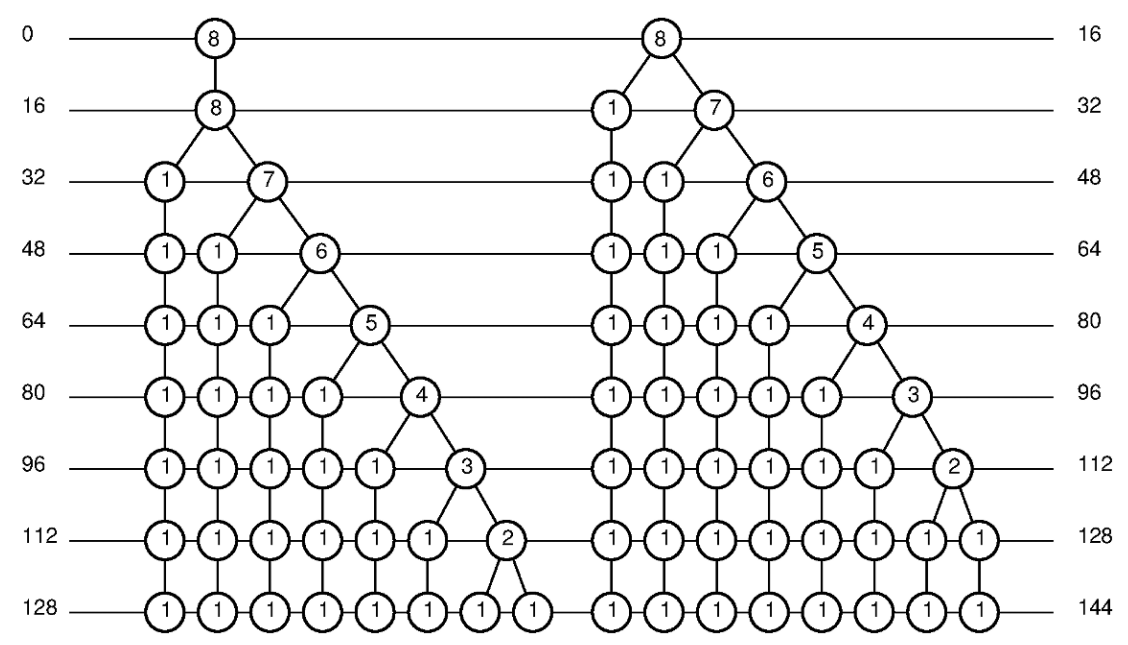

Figura 9: Floresta $\Omega_{2}$ de árvores de tempos do intervalo 8:9-segunda maior no estado alto, $1^{\text {a }}$ mutação, $d_{0}=18$.

Da mesma forma, assim como se procedeu com a floresta $\Omega_{1}$ acima, a coleta de notas na floresta $\Omega_{2}$ se inicia no nodo raiz da árvore mais à esquerda, isto é, a duração \{8\}, que é sucedida pela raiz $\{8\}$ da segunda árvore, chamada árvore telescópica ${ }^{17}$. Em seguida, considera-se a segunda geração de durações, de modo que o nodo descendentes $\{8\}$ da primeira raiz é coletado, aí então tomam-se os descendentes $\{17\}$ da raiz da segunda árvore. A terceira geração produz $\left\{\begin{array}{ll}1 & 7\end{array}\right\}$ e $\left\{\begin{array}{lll}1 & 1 & 6\end{array}\right\}$. A quarta geração por sua vez produz $\left\{\begin{array}{lllll}1 & 1 & 6\end{array}\right\}$ e $\left\{\begin{array}{lll}1 & 1\end{array}\right.$ $15\}$. A quinta geração produz $\left\{\begin{array}{llll}1 & 1 & 1 & 5\end{array}\right\}$ e $\left\{\begin{array}{llllll}1 & 1 & 1 & 1 & 4\end{array}\right\}$. A sexta geração produz $\left\{\begin{array}{lllll}1 & 1 & 1 & 1 & 4\end{array}\right\}, \begin{cases}1 \\ 1\end{cases}$ $\left.\begin{array}{lllll}1 & 1 & 1 & 1 & 3\end{array}\right\}$. A sétima geração produz $\left\{\begin{array}{llllll}1 & 1 & 1 & 1 & 1 & 3\end{array}\right\}$ e $\left\{\begin{array}{lllllll}1 & 1 & 1 & 1 & 1 & 1 & 2\end{array}\right\}$. A oitava geração produz

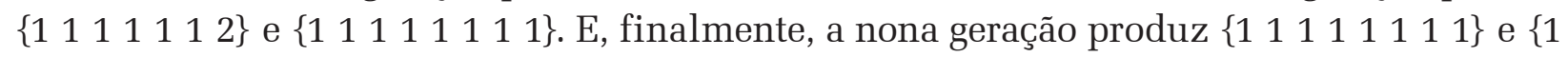
$1111111\}$.
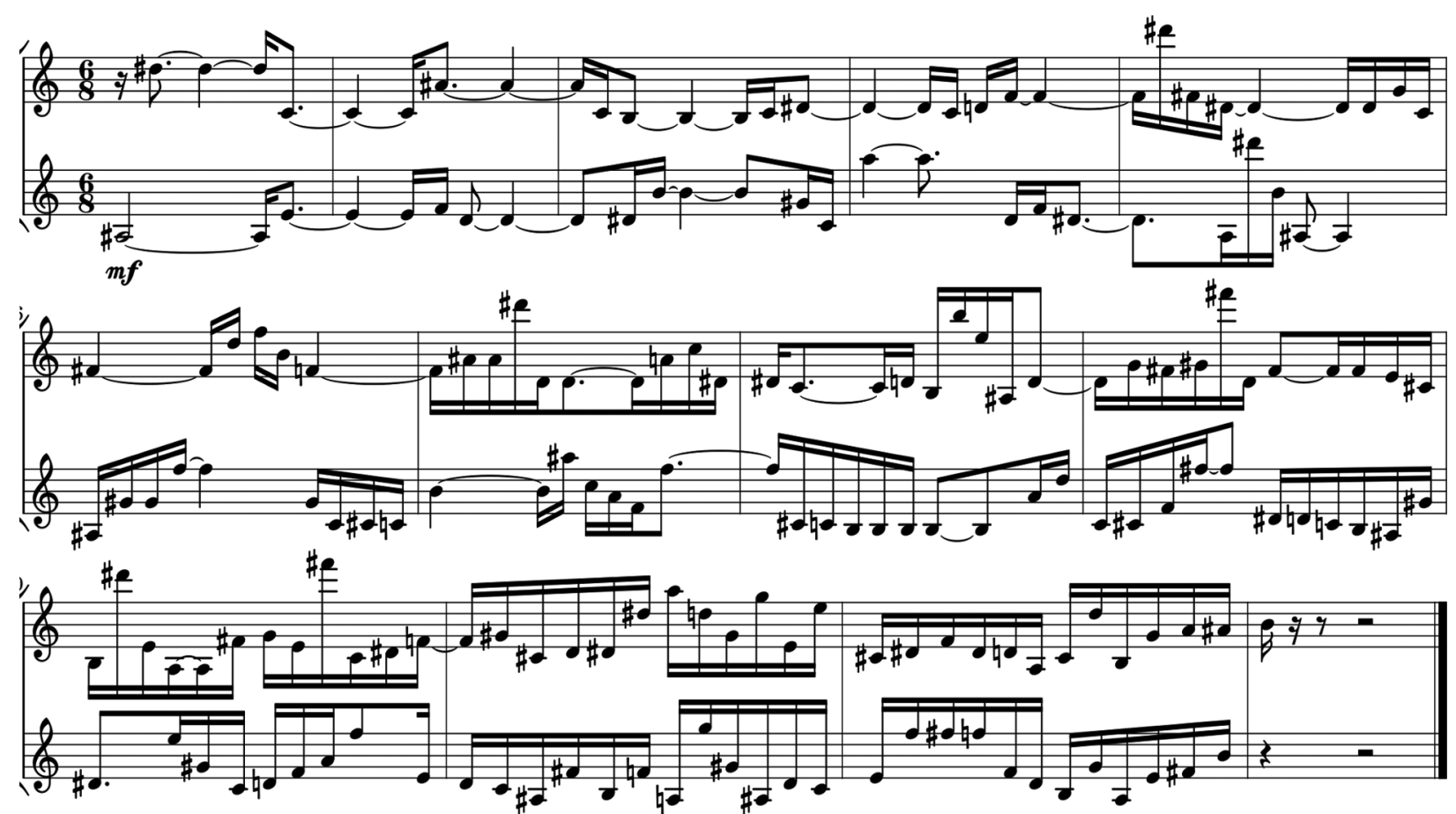

Figura 10: Contraponto $C_{2}$ decifrado no interior de uma segunda maior (8:9) em equilíbrio. (Áudio on-line disponível em LAMUS 2013a.)

Por construção, o contraponto $C_{2}$ é do tipo $D D$, (direta $\times$ direta). Com as sequências de durações produzidas pelas florestas $\mathrm{A}_{2}$ e $\Omega_{2}$, dois padrões rítmicos $R_{2 \mathrm{~B}}$ e $R_{2 \mathrm{~A}}$ são formados 
a partir das durações dos respectivos eventos. A Figura 10 mostra a disposição das melodias $M_{2 \mathrm{~B}}$ e $M_{2 \mathrm{~A}}$ calculadas para cada um desses dois padrões rítmicos, isto depois que o objeto intervalar é posicionado no espaço. A escrita se faz em doze compassos em uma fórmula de compasso de 6/8, uma vez que a duração total da sequência é de 144 passos de tempo. Em outras palavras, dispondo-se 12 passos (isto é, seis colcheias) em cada compasso, todo o contraponto $C_{2}$ estará acomodado em doze compassos.

\section{Contraponto $C_{3}$ no interior de uma décima sexta diminuta [3:13]}

Também neste terceiro e último caso contrapontístico $C_{3}$, a descrição será mais abreviada, uma vez que os procedimentos iniciais são semelhantes. Fica implícito que os ritmos $R_{3 \mathrm{~B}}$ е $R_{3 \mathrm{~A}}$ serão decifrados, assim como as melodias $M_{3 \mathrm{~B}}$ e $M_{3 \mathrm{~A}}$ serão calculadas.

Os parâmetros do primeiro objeto intervalar conjugado de uma décima sexta diminuta [3:13], quais sejam, posição, orientação, assim como razão intervalar [m:n], amplitude (a) do MHS, fase inicial ( $\varphi$ ), juntamente com o raio (b) do MCU, o giro inicial $(\theta)$, e os fatores melódicos $\left(k_{\mathrm{A}}, k_{\mathrm{T}}\right.$ e $k_{\mathrm{D}}$ ) estão na Tabela 5 . Este objeto intervalar contém a melodia $M_{3 \mathrm{~B}}$. Sendo a relação de equilíbrio dada por $a m^{2}=b n^{2}$, o valor do raio $b$ do MCU será um pouco reduzido (teoricamente por um infinitésimo), de tal maneira que o objeto pertencerá ligeiramente ao estado baixo.

Tabela 5: Primeiro objeto intervalar conjugado de uma décima sexta diminuta [3:13] ligeiramente no estado baixo.

\begin{tabular}{|c|c|c|c|c|c|c|c|c|c|c|c|c|c|c|c|c|}
\hline & $a$ & $m$ & $\varphi$ & $b$ & $n$ & $\theta$ & $p_{\mathrm{x}}$ & $p_{\mathrm{y}}$ & $p_{\mathrm{z}}$ & $\rho_{\mathrm{x}}$ & $\rho_{\mathrm{y}}$ & $\rho_{\mathrm{z}}$ & $k_{\mathrm{A}}$ & $k_{\mathrm{T}}$ & $k_{\mathrm{D}}$ & sentido \\
\hline $\mathrm{MHS}$ & 45 & 3 & 127 & & & & & & & & & & & & & \\
\hline MCU & & & & 2,395 & 13 & -1 & & & & & & & & & & Anti-horário \\
\hline Posição & & & & & & & 11 & 27 & 18 & & & & & & & \\
\hline Orientação & & & & & & & & & & 128 & 221 & 59 & & & & \\
\hline Fatores & & & & & & & & & & & & & 6 & 7 & 2 & \\
\hline
\end{tabular}

Quanto ao segundo objeto intervalar conjugado deste terceiro contraponto, considera-se outra vez a relação de equilíbrio $a m^{2}=b n^{2}$ como ponto de partida, e aumenta-se um pouco (teoricamente um infinitésimo) o valor do parâmetro $b$ - correspondente ao raio do MCU do primeiro objeto - de modo a tornar-se agora a amplitude do novo MHS, de tal maneira que este segundo objeto pertencerá ligeiramente ao estado alto. $\mathrm{O}$ valor do parâmetro $a$, correspondente à amplitude do MHS do primeiro objeto, tornar-se-á o raio do novo MCU, cujo sentido de rotação é anti-horário, de modo que a ordenação melódica correspondente será direta. Os parâmetros deste segundo objeto intervalar conjugado da décima sexta diminuta [3:13] estão na Tabela 6. A melodia $\mathrm{M}_{3 \mathrm{~A}}$ está contida neste segundo objeto intervalar.

Tabela 6: Segundo objeto intervalar conjugado de uma décima sexta diminuta [3:13] ligeiramente no estado alto.

\begin{tabular}{|c|c|c|c|c|c|c|c|c|c|c|c|c|c|c|c|c|}
\hline & $a$ & $m$ & $\varphi$ & $b$ & $n$ & $\theta$ & $p_{x}$ & $p_{y}$ & $p_{z}$ & $\rho_{x}$ & $\rho_{y}$ & $\rho_{z}$ & $k_{A}$ & $k_{T}$ & $k_{D}$ & sentido \\
\hline MCU & 45 & 3 & 127 & & & & & & & & & & & & & Anti-horário \\
\hline MHS & & & & 2,397 & 13 & -1 & & & & & & & & & & \\
\hline Posição & & & & & & & 11 & 27 & 18 & & & & & & & \\
\hline Orientação & & & & & & & & & & 128 & 221 & 59 & & & & \\
\hline Fatores & & & & & & & & & & & & & 6 & 7 & 2 & \\
\hline
\end{tabular}

Neste caso, onde se estuda uma décima sexta diminuta [3:13] como objeto primal, há oito árvores de tempos na floresta $\mathrm{A}_{3}$ no estado baixo, na sua oitava mutação, conforme ilustra a Figura 11. Tal floresta $\mathrm{A}_{3}$ é uma das treze hierarquias temporais que se podem extrair do interior de uma décima sexta diminuta-3:13 no estado baixo. 


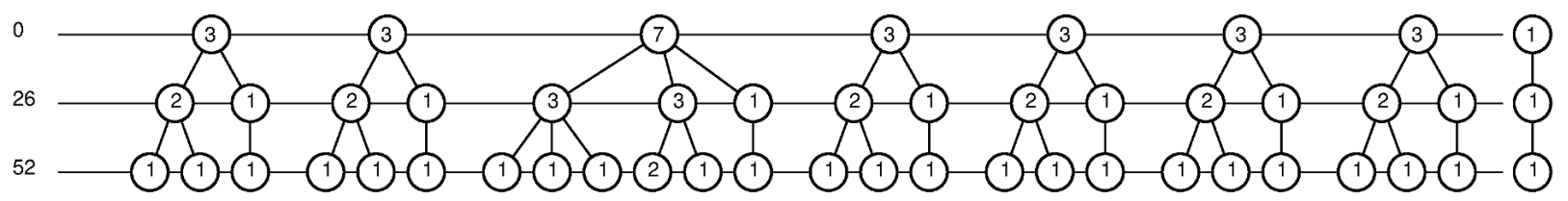

Figura 11: Floresta $A_{3}$ de árvores de tempos do intervalo 3:13-décima sexta diminuta no estado baixo., $8^{a}$ mutação, $d_{0}=13$.

Assim como nas florestas $A_{1}$ e $A_{2}$ acima, a coleta de notas na floresta $A_{3}$ se inicia no nodo raiz da árvore mais à esquerda, isto é, a duração $\{3\}$, que é seguida pela raiz da segunda árvore $\{3\}$, seguida pela raiz da terceira árvore $\{7\}$, seguida pela raiz da quarta árvore $\{3\}$, seguida pela raiz da quinta árvore $\{3\}$, seguida pela raiz da sexta árvore $\{3\}$, seguida pela raiz da sétima árvore $\{3\}$ e, então, como último elemento do primeiro nível (ou geração) da floresta, o nodo raiz da oitava árvore $\{1\}$ é coletado. Considera-se então a segunda geração de durações, de onde, primeiramente, os dois nodos descendentes $\left\{\begin{array}{ll}2 & 1\end{array}\right\}$ da primeira raiz são coletados. Depois, tomam-se os descendentes $\left\{\begin{array}{l}2 \\ 1\end{array}\right\}$ da raiz da segunda árvore, os descendentes $\left\{\begin{array}{lll}3 & 3 & 1\end{array}\right\}$ da terceira árvore, os descendentes $\left\{\begin{array}{ll}2 & 1\end{array}\right\}$ da quarta árvore, os descendentes $\left\{\begin{array}{ll}2 & 1\end{array}\right\}$ da quinta árvore, os descendentes $\left\{\begin{array}{ll}2 & 1\end{array}\right\}$ da sexta árvore, os descendentes $\left\{\begin{array}{ll}2 & 1\end{array}\right\}$ da sétima árvore e, para concluir este segundo nível, toma-se o descendente $\{1\}$ da oitava árvore. Finalmente, a terceira geração produz $\left\{\begin{array}{lll}1 & 1 & 1\end{array}\right\},\left\{\begin{array}{llll}1 & 1 & 1\end{array}\right\},\left\{\begin{array}{llllll}1 & 1 & 1 & 2 & 1 & 1\end{array}\right\},\left\{\begin{array}{lllll}1 & 1 & 1\end{array}\right\},\left\{\begin{array}{llll}1 & 1 & 1\end{array}\right\}$, $\left\{\begin{array}{lll}1 & 1 & 1\end{array}\right\},\left\{\begin{array}{lll}1 & 1 & 1\end{array}\right\},\left\{\begin{array}{lll}1 & 1 & 1\end{array}\right\}$ e $\begin{cases}1 \\ \text {. }\end{cases}$

Quanto à floresta $\Omega_{3}$ mostrada na Figura 12, como em toda floresta do estado alto, há apenas duas árvores de tempos. No caso em estudo, $\Omega_{3}$ é a floresta ômega de uma décima sexta diminuta [3:13] no estado alto, na sua terceira mutação. Tal floresta $\Omega_{3}$ é uma das três hierarquias temporais que se podem criar no interior de tal intervalo no estado alto.

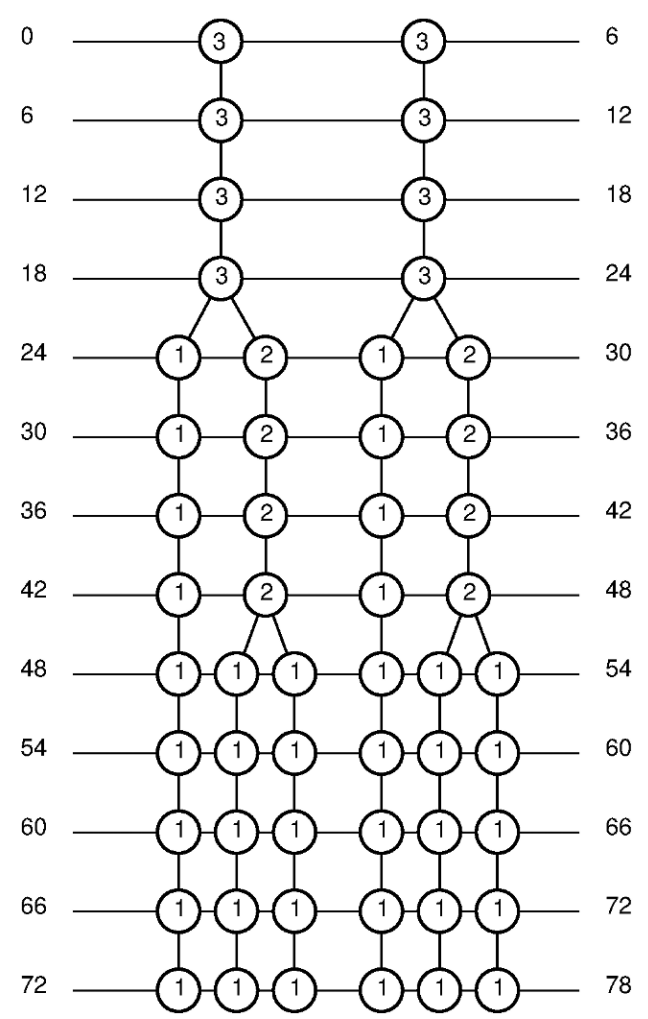

Figura 12: Floresta $\Omega_{3}$ de árvores de tempo de uma décima sexta diminuta (3:13) no estado alto; ritmo da $3^{a}$ mutação, do $=28$. 
A coleta de notas na floresta $\Omega_{3}$ se inicia no nodo raiz da árvore mais à esquerda, isto é, a duração $\{3\}$, que é sucedida pela raiz da segunda árvore $\{3\}$. Em seguida, considera-se a segunda geração de durações, de modo que o único nodo descendente $\{3\}$ da primeira raiz é coletado. Toma-se então o descendente $\{3\}$ da raiz da segunda árvore. A terceira geração produz $\{3\}$ e $\{3\}$. A quarta geração por sua vez também produz $\{3\}$ e $\{3\}$. A quinta geração produz $\left\{\begin{array}{lll}1 & 2\end{array}\right\}$ e $\left\{\begin{array}{lll}1 & 2\end{array}\right\}$. A sexta geração também produz $\left\{\begin{array}{llll}1 & 2\end{array}\right\}$ e $\left.\begin{array}{lll}1 & 2\end{array}\right\}$. A sétima geração também produz $\left\{\begin{array}{lll}1 & 2\end{array}\right\}$ e $\left\{\begin{array}{lll}1 & 2\end{array}\right\}$. A oitava geração também produz $\left\{\begin{array}{lll}1 & 2\end{array}\right\}$ e $\left\{\begin{array}{lll}1 & 2\end{array}\right\}$. A nona geração produz $\left\{\begin{array}{lll}1 & 1 & 1\end{array}\right\}$ e $\left\{\begin{array}{lll}1 & 1 & 1\end{array}\right\}$. A décima geração produz $\left\{\begin{array}{lll}1 & 1 & 1\end{array}\right\}$ e $\left.\begin{array}{llll}1 & 1 & 1\end{array}\right\}$. A décima primeira também geração produz $\left\{\begin{array}{lll}1 & 1 & 1\end{array}\right\}$ e $\left\{\begin{array}{lll}1 & 1 & 1\end{array}\right\}$. A décima segunda também geração produz $\left\{\begin{array}{lll}1 & 1 & 1\end{array}\right\}$ e $\left\{\begin{array}{lll}1 & 1 & 1\end{array}\right\}$. E finalmente a décima terceira segunda também geração produz $\left\{\begin{array}{lll}1 & 1 & 1\end{array}\right\}$ e $\left\{\begin{array}{lll}1 & 1 & 1\end{array}\right\}$.

Assim como no exemplo anterior, por construção, o contraponto $C_{3}$ é do tipo $D D$, (ordenação direta $\times$ ordenação direta). A partir das sequências de durações extraídas de $\mathrm{A}_{3}$ e $\Omega_{3}$, dois padrões rítmicos $R_{3 \mathrm{~B}}$ е $R_{3 \mathrm{~A}}$ são formados a partir das durações dos respectivos eventos. A Figura 13 mostra a disposição das melodias $M_{3 \mathrm{~B}}$ е $M_{3 \mathrm{~A}}$ calculadas para cada um desses dois padrões rítmicos depois que o objeto intervalar é posicionado no espaço. A escrita se faz em seis compassos sob uma fórmula de compasso de 4/4, uma vez que a duração total da sequência é de 78 passos de tempo. Em outras palavras, dispondo-se 16 passos (isto é, quatro semínimas) por compasso, todo o contraponto $C_{3}$ acomoda-se em um total de seis compassos.

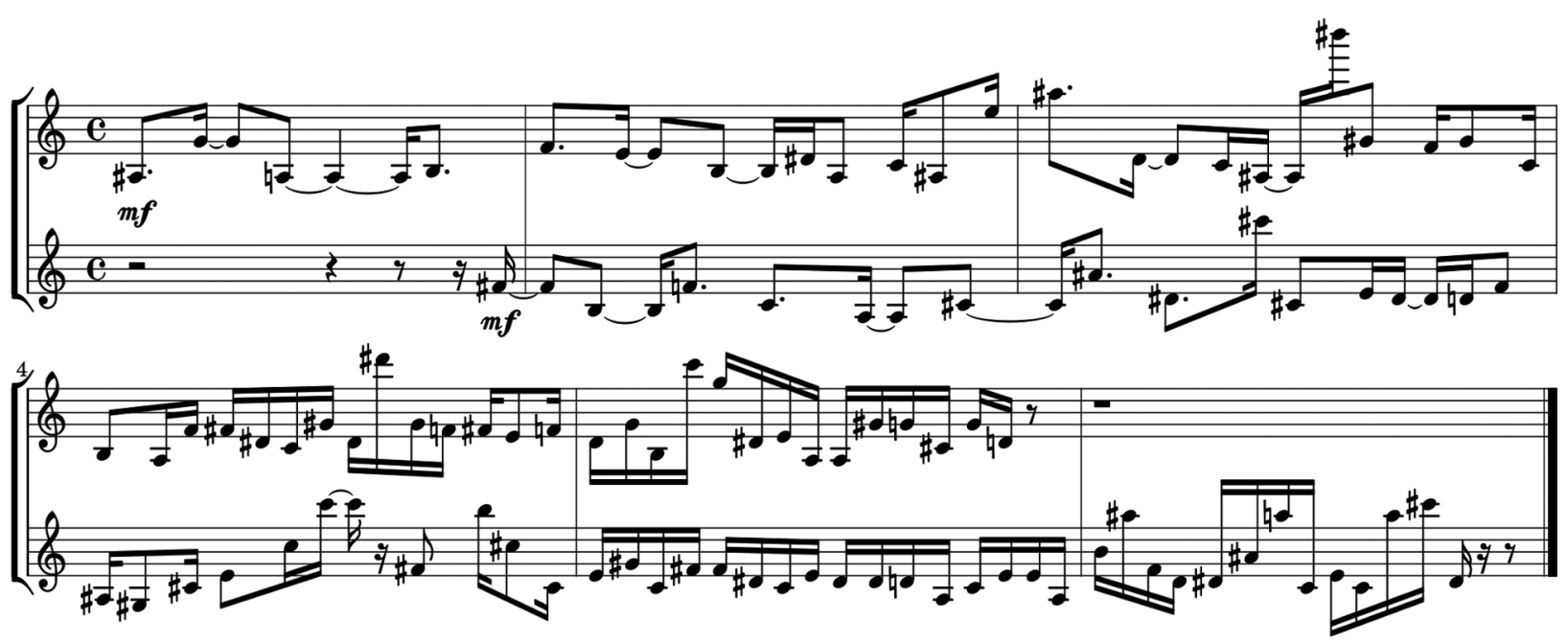

Figura 13: Contraponto $C_{3}$ decifrado no interior de uma décima sexta diminuta (3:13) em equilíbrio. (Áudio on-line disponível em LAMUS 2013a.)

Os três exemplos de contraponto intervalar descritos acima ilustram a essência do método e os resultados musicais que se obtêm quando se manipula o intervalo em equilíbrio. Ainda que os contrapontos estudados $C_{1}, C_{2}$ e $C_{3}$ sejam estruturas elementares e, portanto, incompletas, do ponto de vista da construção musical, deve-se considerar que eles são tais que poderão vir a crescer segundo modos corretos e consistentes dentro da teoria das árvores de tempos. Primeiramente, deverão crescer verticalmente, para que se arme a estrutura harmônica. Em seguida, deverão crescer horizontalmente, para que se completem as vozes com a justaposição de melodias geradas por objetos intervalares de segunda ordem. Desta maneira, será possível sair-se da condição de comportamento polifônico primitivo do espaço-tempo intervalar para a de uma composição polifônica inteira. 


\section{Considerações finais}

Abordou-se neste artigo a existência de uma metodologia composicional própria para a criação de contrapontos bem formados, metodologia esta que se fundamenta nos fenômenos pertencentes ao interior do intervalo musical, desde que este se encontre no estado de equilíbrio. Nestas condições, extraem-se do intervalo duas melodias concorrentes, as quais, em conjunto, apresentam um grau de coesão suficiente para que o encontro entre elas ocorra de maneira significativa e natural no espaço-tempo da música. Os três contrapontos estudados, embora sejam estruturas musicais pequenas e incompletas, mostram o caminho a ser seguido se o objetivo for a construção de peças polifônicas mais complexas e completas.

No caso das árvores de tempos, a dimensão harmônica se estabelece quando, a cada nota extraída, são extraídas também todas as notas, descendentes dela própria, na hierarquia da árvore à qual pertence. Desta maneira, todos os níveis da subárvore que tem o nodo (a nota) da vez como raiz iniciar-se-ão acusticamente ao mesmo tempo, gerando-se assim um grupo de notas concomitantes.

A exemplo do contraponto central, a inclusão de outras partes concorrentes, que poderão vir a constituir uma estrutura polifônica bem formada em torno do contraponto intervalar primal, também dependerá inteiramente de notas e valores calculados na cinemática do objeto intervalar e na topologia de suas árvores de tempos.

Por fim, assim como o contraponto intervalar segue outros caminhos, que não os definidos pelas regras descritas nos tratados de contraponto - a despeito de ser igualmente contraponto, tanto em conceito quanto em resultados - também com relação à harmonia que se produzirá pelo ajuntamento ao contraponto central de outras vozes intervalares secundárias, não se utilizam diretamente os preceitos que se encontram nos tratados de harmonia, muito embora haja fundamentação científica notável em algumas obras, sobretudo quando se leva em conta a época em que foram escritas, como em J. P. Rameau em 1722 (v. RAMEAU, 1971).

Em composição formal com as árvores de tempos, entretanto, o próprio processo de cálculo das células contrapontísticas cuidará da harmonia intervalar, que deverá indispensavelmente ser harmonia do mesmo jeito, sempre porque haverá de ser avaliada por ouvintes qualificados, como os músicos e os apreciadores da música em geral.

\section{Notas}

1 O intervalo musical considerado neste artigo é o intervalo justo. Mais precisamente, assume-se o intervalo como sendo um sistema de dois sons senoidais concorrentes, cuja razão de frequências é uma razão de dois inteiros primos entre si, inteiros estes representados por $[m: n]$. Vale dizer, o único número que se constitui em um fator comum a ambos os inteiros $[m]$ e $[n]$ é a unidade, isto é, mdc $(m, n)=1$. Por estão razão, os números $[m]$ e $[n]$ são denominados números harmônicos reduzidos. Além disso, assume-se que $m<n$, de modo que $[m]$ corresponde ao som baixo, ao passo que [n] corresponde ao som alto. Uma propriedade relevante dos intervalos justos é o fato de terem um período bem definido, isto é, calculável, (v. ARCELA, 2008, Section 2), que é um espaço de tempo representado aqui neste trabalho por $\tau$. A importância do intervalo musical na construção da música está registrada em uma infinidade de obras da literatura concernente à teoria da música. Alguns argumentos sobre tal importância podem ser vistos em HINDEMITH, 1968, LEWIN, 1987, ARCELA, 2013.

2 As árvores de tempos são estruturas de dados computáveis - antes de mais nada, são estruturas nativas do mundo interior dos intervalos musicais - as quais são capazes de reunir tempo e espaço numa única peça de informação. Ver ARCELA, 1986, 2000, 2013 (Chapter 5: Forests Alpha and Omega).

3 O objeto intervalar é um modelo formal para o intervalo musical que se baseia na composição ortogonal de movimentos periódicos. (v. ARCELA, 2013, Section 2.4) 
4 Espaço-tempo intervalar é uma expressão inspirada no conceito de espaço-tempo, que é próprio da teoria da relatividade. O seu emprego neste artigo ocorre não como uma "licença poética" mas sim para valorizar algumas semelhanças que há entre estes dois mundos, o da música intervalar e o da física relativística.

${ }^{5}$ Objeto intervalar primal se refere a um tipo de construção melódica inteiramente dentro da significação do conteúdo intervalar enquanto árvores de tempos. A avaliação melódica do objeto primal é de suma importância para que os objetos secundários tenham conteúdo musical consistente.

${ }_{6}$ Trata-se da organização hierárquica das árvores de tempos, isto é, diz respeito ao sistema de parentesco, ascendência e descendência que há entre os nodos de uma mesma árvore. Há uma harmonia intervalar que pode ser computada em função de tal organização.

7 O objeto intervalar - enquanto primeiro estágio do modelo para o intervalo - é descrito formalmente em ARCELA, 2013, (Chapter 2: Modelling Musical Intervals - Section: The Intervallic Object).

${ }^{8}$ Quando o intervalo se encontra em equilíbrio, a força da altura (pitch strength, v. FASTL e STOLL, 1979) é a mesma para ambas as componentes intervalares, isto é, os sons baixo e alto.

9 Grau de coesão é uma expressão adaptada do termo "aderência à tonalidade” usado em SCHOENBERG, 1963, p. 12, §10. Na acepção pretendida neste artigo, indica a afinidade entre as melodias sob contraponto. Poder-se-ia dizer numa equação simples: grau de coesão é igual à aderência à tonalidade mais a confluência rítmica entre as duas melodias.

${ }^{10}$ Os diversos tipos de caminhamento em árvores são um tópico central na área de estruturas de dados. (v. KNUTH, 1968). O caminhamento por entre os nodos das árvores de tempos usado na extração de padrões rítmicos é um percurso (próprio para árvores) denominado "primeiro em largura". Em inglês, breadth-first traversal of trees.

${ }^{11}$ Evento é o nome dado a cada um dos nodos das árvores de tempos. Cada um deles possui um instante de surgimento e um tempo de vida, que corresponde (é proporcional) ao número inteiro existente no próprio nodo. Na sua tradução musical, o evento nada mais é do que uma nota, cujos valores de altura (frequência) e intensidade são calculados na cinemática intervalar.

12 A cinemática intervalar é um tópico discutido conceitual e matematicamente em ARCELA, 2013, Chapter 2: Modelling Musical Intervals, Section 2.4: Intervallic Object. Ver também o Applet 2.4.3: Combined Motion.

${ }^{13}$ Para sons puros (senoidais), a força da altura é definida como sendo o produto da amplitude pelo quadrado da frequência (v. ARCELA, 2008). O conceito de força da altura é derivado do conceito de pitch strength que se encontra em FASTL e STOLL, 1979.

${ }^{14}$ As árvores de tempos - enquanto estágio final do modelo para o intervalo - são discutidas algoritmicamente com base em estruturas de dados arborescentes, e em termos de teoria da música quanto ao papel que a partícula intervalar desempenha na construção musical, em ARCELA, 2013, Chapter 5: Forests Alpha and Omega.

15 Também denominada composição algorítmica. Entretanto, pode-se argumentar que se trata de uma qualificação desnecessária, já que, via de regra, toda composição será sempre algorítmica, isto é, a sua construção deverá ter seguido uma sequência de passos formais (metodológicos), seja em uma composição do século XVI (ex. Palestrina), seja algo escrito no século XX (ex. Schoenberg).

${ }^{16}$ A composição de melodias com estruturas formais é um assunto explorado por vários autores, pelo menos desde os anos 1950, sob diferentes abordagens. Qualquer que seja o modelo empregado - processos estocásticos [XENAKIS, 1957], sistemas baseados em regras [HILLER e BAKER 1964; HILLER, 1969], estruturas linguísticas [LINDBLOM e SUNDBERG, 1969; LASKE, 1973; SUNDBERG e LINDBLOM, 1976; LERDAHL e JAKENDOFF, 1983], ou ainda, como é o caso do presente artigo, árvores de tempos - o objetivo é um sistema musical com o qual seja possível inferir ou calcular melodias.

17 Em intervalos no estado baixo, o número de árvores de tempos da floresta vai desde um mínimo de três - para intervalos menores do que uma oitava - até uma quantidade que depende de quantas oitavas há entre os sons alto e baixo. Há quatro tipos de árvores no estado baixo, quais sejam, primordial, complexa, especular e residual, sendo a árvore especular uma subárvore da árvore complexa. Já no estado alto, a floresta omega contém apenas duas árvores: a esquerda e a telescópica. Em contrapartida, as gerações de cada uma das duas árvores podem se repetir várias vezes (sem ramificação), a depender da largura do intervalo, isto é, de quantas oitavas há entre os sons alto e baixo.

\section{Referências}

ARCELA, Aluizio. Time trees: the inner organization of intervals. in International Computer Music Conference, Proceedings of the $12^{\text {th }}$ ICMC, Haia. San Francisco, CA: Computer Music Association, 1986, p. 87-89.

. Time trees as virtual worlds. Electronic Musicological Review, 6, 2001. Publicado também nos Anais do VII Simpósio Brasileiro de Computação e Música, Curitiba: Sociedade Brasileira de Computação, 2000. 
2008.

The computation of pitch with vectors. J. Braz. Comp. Soc., Rio de Janeiro, 14(3):65-85,

. Melodias em épura. Revista Música em Contexto, Brasília, v.1, Ano 6:85-95, 2012.

. About time trees. Tradução para o inglês da tese de doutorado Arcela, A. "As árvores de tempos e a configuração genética dos intervalos musicais”, PUC-Rio, 1984, com inserções de textos complementares, imagens, áudio, autômatos sônicos e partituras. Publicação web: UnB, Agosto 2013. Disponível em: <http://www.cic.unb.br/docentes/lcmm/att/>. Data do acesso: $23 / 10 / 2013$.

. Deciphering rhythms from intervals. (a ser publicado em 2014).

FASTL, Hugo; STOLL, G. Scaling of pitch strength. Hearing Research, 119:293-301, 1979.

HILLER, Lejaren. Some compositional techniques involving the use of computers. In: H. Von Foerster; J. W. Beauchamps (Orgs), Music by computers, p. 71-83, Nova Iorque: Wiley, 1969.

HILLER, Lejaren; BAKER, R. A. Computer cantata: an investigation of compositional procedure. Perspectives of New Music 3:62-90, 1964.

HINDEMITH, Paul. The craft of musical composition, Nova Iorque: Schott, v.1, p. 57-64, 1968.

KNUTH, Donald E. The art of computer programming, Boston: Addison-Wesley, v.1, p. 315-406, 1968.

KRENEK, Ernst. Studies in counterpoint - based on the twelve-tone technique, Nova Iorque: Schirmer, 1940.

LAMUS, UnB-Website. Contrapontos calculados: Áudio online dos casos abordados neste artigo. Laboratório de Acústica Musical, Universidade de Brasília, 2013(a). Disponível em: <http://www.cic.unb.br/docentes/lcmm/cceti/>. Data do acesso: 10/11/2013.

LAMUS, UnB-Website. Deciphering rhythms: Áudio online dos casos abordados no artigo "Deciphering rhythms from intervals", a ser publicado. Laboratório de Acústica Musical, Universidade de Brasília, 2013(b). Disponível em: <http://www.cic.unb.br/docentes/lcmm/ drfi/>. Data do acesso: 10/11/2013.

LASKE, Otto E. In search of a generative grammar for music. Perspectives of New Music, 12(1):351-378, 1973.

LERDAHL, Fred; JAKENDOFF, R. S. A generative theory of tonal music. Cambridge: MIT Press, 1983.

LEWIN, David. Generalized musical intervals and transformations. New Have: Yale University Press, 1987.

LINDBLOM, Björn; SUNDBERG, J. Towards a generative theory of melody. STL-QPSR, 10(4): 53-86, 1969.

OWEN, Harold. Modal and tonal counterpoint from Josquin to Stravinsky, Nova Iorque: Schirmer, 1992.

RAMEAU, Jean-Philippe. Treatise on harmony, Tradução de Philip Gossett do livro Traité de l'harmonie - Reduite à ses principes naturels (1722). Nova Iorque: Dover, 1971.

SCHOENBERG, Arnold. Preliminary exercises in counterpoint, volume 1. Londres: Faber, 1963. 
XENAKIS, Iannis. A la recherche d'une musique stochastique. Gravesaner Blätter, n.11/12, Ars Viva Verlag, 1957.

ZARLINO, Gioseffo. The art of counterpoint, Parte 3 de Le Istitutioni Harmoniche (1558). Traduzido por Guy A. Marco e Claude V. Palisca. Nova Iorque: Norton, quarta edição, 1968.

Aluizio Arcela - Professor da Universidade de Brasília. Doutor em Ciências (programação e teoria da computação) pela PUC-Rio, com tese defendida sobre um modelo matemático para o intervalo musical (1984). Fundador da área de computação sônica no Departamento de Ciência da Computação, atualmente leciona acústica musical no Departamento de Música. 